\title{
ISOLATION AND CHARACTERIZATION OF SESQUITERPENE LACTONES FROM Calea uniflora LesS. AND THEIR LEISHMANICIDAL AND TRYPANOCIDAL ACTIVITIES
}

\author{
Tamires C. Lima ${ }^{\mathrm{a}, *,(1)}$, Rafaela J. Souza ${ }^{\mathrm{b}}$, Milene H. Moraes ${ }^{\mathrm{c}}$, Saulo S. Matos ${ }^{\mathrm{a}}$, Fernando H. O. Almeida ${ }^{\mathrm{a}}$, Mário Steindel \\ and Maique W. Biavatti ${ }^{b}$ \\ aDepartamento de Farmácia, Universidade Federal de Sergipe, 49100-000 São Cristóvão - SE, Brasil

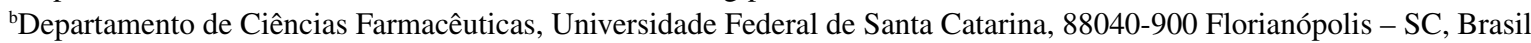 \\ 'Departamento de Microbiologia e Parasitologia, Universidade Federal de Santa Catarina, 88040-900 Florianópolis - SC, Brasil
}

Recebido em 17/10/2020; aceito em 03/02/2021; publicado na web em 26/02/2021

\begin{abstract}
Calea uniflora Less., commonly known in Brazil as "erva-de-lagarto" and "arnica-da-praia", is used in folk medicine to treat internal and external bruises and as anti-inflammatory. However, despite the popular use there is a lack of information in terms of isolation and biological evaluation of its secondary metabolites. Thus, the aims of this study were to identify and characterize compounds of C. uniflora leaves with trypanocidal and leishmanicidal potential. Methods: Structures of compounds were determined by HRESIMS spectra, and 1D and 2D NMR spectra. Then, they were tested for in vitro leishmanicidal and trypanocidal activities against Leishmania amazonensis and Trypanosoma cruzi intracellular amastigotes, respectively. Results: Four germacranolide-type sesquiterpene lactones were isolated and characterized from dichloromethane fraction: $2 \alpha$-hydroxy- $8 \beta-2^{\prime}, 3^{\prime}, 5^{\prime}$-trihydroxy-angeloyloxycostunolide (1), desacetyleupaserrin (2), $2 \alpha$-hydroxy-8 $\beta$-3'-hydroxy-2',5'-epoxyangeloyloxycostunolide (3) and ovatifolin (4). All compounds are described herein for the first time for $C$. uniflora and Calea genus. Lactones 1, 2 and $\mathbf{4}$ demonstrated weak or no inhibition of the T. cruzi amastigotes, whereas compound $\mathbf{3}$ revealed a moderate effect (36.8\%). Regarding the leishmanicidal activity, 4 exhibited a $59.9 \%$ inhibitory effect on the growth of L. amazonensis. Conclusion: None of the isolated compounds presented promising trypanocidal effect and $\mathbf{4}$ was the most active compound against $L$. amazonensis amastigotes.
\end{abstract}

Keywords: Asteraceae; antiprotozoal activity; Calea uniflora; sesquiterpene lactones.

\section{INTRODUCTION}

Calea uniflora Less., belonging to the Asteraceae family (tribe Heliantheae, subtribe Ecliptinae), is a perennial and subshrub herb with yellow inflorescences. ${ }^{1}$ Commonly known in Brazil as "ervade-lagarto" and "arnica-da-praia", ${ }^{2,3}$ this species is native to South America (Uruguay, Paraguay, Argentine, and Southern Brazil). In Southern Brazil, C. uniflora aerial parts are widely used by local population as anti-inflammatory, for wound healing, in treatment of internal and external bruises, as antiseptic (to treat mosquito bites), for rheumatism, and to treat urinary infections and flu. ${ }^{4}$

Few studies have been carried out on the chemical analysis and pharmacological properties of $C$. uniflora. Earlier investigations in different parts of the plant revealed the presence of the following secondary metabolites: $p$-hydroxyacetophenones derivatives, ${ }^{5}$ chromanones, ${ }^{6}$ chromones, flavonoids aglycones and heterosides, chalcones and phenolic acids. ${ }^{7}$ Regarding the biological activity, this species and/or its isolated compounds revealed leishmanicidal, ${ }^{6}$ antinociceptive, cytotoxic, ${ }^{8}$ anti-inflammatory, ${ }^{9}$ trypanocidal, and leishmanicidal activities. ${ }^{7}$

Phytochemical studies conducted on Calea species have confirmed that this genus is rich in sesquiterpenes lactones, an attractive chemical class in the search for bioactive molecules. Several pharmacological effects have been reported for sesquiterpene lactones, including anticancer, ${ }^{10}$ anti-inflammatory, ${ }^{11}$ antidiabetic, ${ }^{12}$ antiprotozoal,${ }^{13}$ and antimycobacterial activities. ${ }^{14}$ However, it is important to emphasize that the toxicological profile of these metabolites must be carefully characterized, since the same activities that make sesquiterpene lactones useful medicines can also cause severe toxicity. ${ }^{15}$

During our investigation, four sesquiterpenes lactones (1-4)

*e-mail: tamires.cl87@gmail.com were isolated and characterized from C. uniflora leaves. Previous investigations reporting the leishmanicidal and trypanocidal effects of natural sesquiterpenes lactones from Calea ${ }^{16,17}$ prompted us to evaluate these compounds against Leishmania amazonensis and Trypanosoma cruzi amastigotes forms.

\section{MATERIAL AND METHODS}

\section{General experimental procedures}

Chemical structures of compounds were determined by melting point (m.p.), NMR spectroscopy and mass spectrometry. 1D and 2D NMR spectra were recorded on Bruker AVANCE spectrometer operating at $600 \mathrm{MHz}$ for ${ }^{1} \mathrm{H}$ and $150 \mathrm{MHz}$ for ${ }^{13} \mathrm{C}$. NMR samples were dissolved in acetone- $d_{6}$, TMS was used as chemical shift reference and coupling constants were quoted in Hertz (Hz). Highresolution electrospray ionization mass spectra (HRESIMS) were measured on a Xevo ${ }^{\circledR} \mathrm{G} 2$-XS Qtof mass spectrometer (Waters).

\section{Plant material}

C. uniflora leaves were collected (October 2012) in Imbituba (2820'36' S; 4867'21'” W), Santa Catarina, Brazil, by Dr. Tamires Cardoso Lima de Carvalho. Plant identification was confirmed by Dr. John Pruski and a voucher specimen (MO-2383317 number) was deposited in New York Botanical Garden Herbarium, New York, United States.

\section{Extraction and isolation of chemical constituents}

Fresh leaves of $C$. uniflora $(2.3 \mathrm{~kg})$ were submitted to static maceration using $92 \%$ ethanol at room temperature for 15 days (three 
extractions). After, solvent was removed at reduced pressure, giving $104 \mathrm{~g}$ of crude extract. Crude extract was subsequently suspended in $\mathrm{H}_{2} \mathrm{O}$ $(500 \mathrm{~mL})$ and partitioned with solvents of increasing polarity (hexane, $\mathrm{CH}_{2} \mathrm{Cl}_{2}$, and EtOAc - 4 × $200 \mathrm{~mL}$ each), yielding hexane $(26.8 \mathrm{~g})$, $\mathrm{CH}_{2} \mathrm{Cl}_{2}(3.2 \mathrm{~g})$ and EtOAc $(6.2 \mathrm{~g})$ fractions, respectively, as well as a residual aqueous fraction that was lyophilized to give $67.8 \mathrm{~g}$ of a hygroscopic solid. Dichloromethane fraction (3.2 g) was subjected to vacuum liquid chromatography (VLC) using silica gel (230-400 mesh) and eluted with hexane, $\mathrm{CH}_{2} \mathrm{Cl}_{2}$, EtOAc and $\mathrm{MeOH}$, pure solvents or in binary solvent mixtures, providing twelve sub-fractions (A, B, C, D, E, F, G, H, I, J, L and M). The following binary mixtures were used: hexane- $\mathrm{CH}_{2} \mathrm{Cl}_{2}(7: 3)$, hexane- $\mathrm{CH}_{2} \mathrm{Cl}_{2}(1: 1)$, hexane- $\mathrm{CH}_{2} \mathrm{Cl}_{2}$ (3:7), pure $\mathrm{CH}_{2} \mathrm{Cl}_{2}, \mathrm{CH}_{2} \mathrm{Cl}_{2}$-EtOAc (9:1), $\mathrm{CH}_{2} \mathrm{Cl}_{2}$-EtOAc (8:2), $\mathrm{CH}_{2} \mathrm{Cl}_{2}$-EtOAc (6:4), $\mathrm{CH}_{2} \mathrm{Cl}_{2}$-EtOAc (4:6), $\mathrm{CH}_{2} \mathrm{Cl}_{2}$-EtOAc (2:8), pure EtOAc, EtOAc-MeOH (7:3), and EtOAc-MeOH (1:1). Sub-fraction $\mathrm{H}$ (650.0 mg) was submitted to silica gel column chromatography (CC, 240-400 mesh) and eluting with a gradient of $\mathrm{CH}_{2} \mathrm{Cl}_{2}$, EtOAc and $\mathrm{MeOH}\left[\mathrm{CH}_{2} \mathrm{Cl}_{2}\right.$-EtOAc (98:2), $\mathrm{CH}_{2} \mathrm{Cl}_{2}$-EtOAc (95:5), $\mathrm{CH}_{2} \mathrm{Cl}_{2}$-EtOAc (9:1), $\mathrm{CH}_{2} \mathrm{Cl}_{2}$-EtOAc (85:15), $\mathrm{CH}_{2} \mathrm{Cl}_{2}$-EtOAc (8:2), $\mathrm{CH}_{2} \mathrm{Cl}_{2}$-EtOAc (7:3), $\mathrm{CH}_{2} \mathrm{Cl}_{2}$-EtOAc (6:4), $\mathrm{CH}_{2} \mathrm{Cl}_{2}$-EtOAc (1:1), $\mathrm{CH}_{2} \mathrm{Cl}_{2}$-EtOAc (3:7), pure EtOAc, and EtOAc-MeOH (1:1)], furnishing 270 fractions (F1-F270). Subsequently, fractions F136-F161 and F174-F186 were combined and purified by preparative TLC $\left[\mathrm{CH}_{2} \mathrm{Cl}_{2}\right.$-EtOAc (7:3)], affording $12.2 \mathrm{mg}$ of the compound $\mathbf{1}$ and $70.0 \mathrm{mg}$ of $\mathbf{2}$, respectively. Sub-fraction F $(660.0 \mathrm{mg})$ was also subjected to silica gel column (230-400 mesh) using hexane, EtOAc and $\mathrm{MeOH}$, pure solvents or binary solvent mixtures, as phase mobile [pure hexane, hexane-EtOAc (95:5), hexane-EtOAc (9:1), hexane-EtOAc (8:2), hexane-EtOAc (7:3), hexane-EtOAc (6:4), hexane-EtOAc (1:1), hexane-EtOAc (3:7), pure EtOAc, EtOAc-MeOH (8:2), and EtOAc-MeOH (1:1)], yielding 240 fractions (F1-F240). Fractions F130-F139 were reunited and purified through preparative TLC $\left[\mathrm{CH}_{2} \mathrm{Cl}_{2}\right.$-EtOAc (7:3)], providing $2.5 \mathrm{mg}$ of compound 3. Additionally, F207-F213 (22.7 mg) was purified by chromatography on a Sephadex LH-20 column using pure acetone as eluent to afford 31 fractions (F1-F31). Fractions F13-F20 were reunited, yielding $5.2 \mathrm{mg}$ of compound 4 .

\section{Physical and spectroscopic data}

Compound 1: Orange oil. ${ }^{1} \mathrm{H}$ NMR (acetone- $d_{6}, 600 \mathrm{MHz}$ ): $\delta_{\mathrm{H}} 6.18$ (d, 3.6, H-13a), 6.01 (ddd, 4.2, 2.8, 1.0, H-8), 5.70 (d, 3.2, H-13b), 5.26 (dd, 9.9, 8.4, H-6), 5.11 (dd, 9.7, 1.2, H-1), 5.05 (dd, 9.9, 1.5, H-5), 4.75 (ddd, 9.7, 9.7, 5.7, H-2), 4.51 (q, 6.6, H-3'), 4.35 (d, 11.2, 5a'), 4.20 (d, 11.2, H-5b'), 3.29 (dddd, 8.4, 3.6, 3.2, 1.0, H-7), 2.72 (dd, 14.4, 4.2, H-9a), 2.66 (dd, 10.9, 5.7, H-3a), 2.57 (dd, 14.4, 2.8, H-9b), 2.07 (m, H-3b), 1.80 (d, 1.5, H-15), 1.61 (d, 1.2, H-14), 1.50 (d, 6.6, H-4'); ${ }^{13} \mathrm{C}$ NMR (acetone- $\left.d_{6}, 150 \mathrm{MHz}\right): \delta_{\mathrm{C}} 170.6\left(\mathrm{C}-1^{\prime}\right)$, 169.7 (C-12), 143.0 (C-4), 137.6 (C-11), 135.8 (C-1), 134.5 (C-10), 130.8 (C-5), 121.7 (C-13), 80.2 (C-2'), 75.7 (C-6), 75.6 (C-8), 69.5 (C-2), 67.3 (C-5'), 59.8 (C-3'), 53.1 (C-7), 49.8 (C-3), 45.1 (C-9), 20.3 (C-14), 19.4 (C-4'), 19.0 (C-15).

Compound 3: White solid. m.p: 190.5-193.0 ${ }^{\circ} \mathrm{C} .{ }^{1} \mathrm{H}$ NMR (acetone- $\left.d_{6}, 600 \mathrm{MHz}\right): \delta_{\mathrm{H}} 6.15$ (d, 3.6, H-13a), 5.96 (ddd, 4.2, 2.6, 1.0, H-8), 5.66 (d, 3.2, H-13b), 5.23 (dd, 9.9, 8.5, H-6), 5.09 (dd, 9.6, 1.0, H-1), 5.05 (dd, 9.9, 1.4, H-5), 4.75 (m, H-2), 4.45 (q, 6.7, H-3'), 3.83 (d, 11.0, 5a'), 3.67 (d, 11.0, H-5b'), 3.24 (dddd, 8.5, 3.6, 3.2, 1.0, H-7), 2.74 (dd, 14.3, 5.2, H-9a), 2.66 (dd, 10.9, 5.8, H-3a), 2.53 (dd, 14.3, 2.6, H-9b), 2.06 (m, H-3b), 1.82 (d, 1.4, H-15), 1.67 (d, 1.0, H-14), 1.44 (d, 6.7, H-4'); ${ }^{13} \mathrm{C}$ NMR (acetone- $d_{6}, 150 \mathrm{MHz}$ ): $\delta_{\mathrm{C}} 172.8\left(\mathrm{C}-1^{\prime}\right), 169.7(\mathrm{C}-12), 143.0(\mathrm{C}-4), 137.8(\mathrm{C}-11), 135.8(\mathrm{C}-1)$, 134.1 (C-10), 130.8 (C-5), 121.6 (C-13), 82.4 (C-2'), 75.8 (C-6), 75.3 (C-8), 69.6 (C-2), 66.2 (C-5'), 60.1 (C-3'), 53.4 (C-7), 49.8 (C-3),
45.2 (C-9), 20.1 (C-14), 19.6 (C-4'), 19.2 (C-15). Positive mode HRESIMS $m / z, 401.1582[\mathrm{M}+\mathrm{Na}]^{+}$(calc. for $\mathrm{C}_{20} \mathrm{H}_{26} \mathrm{NaO}_{7}, 401.1571$ ).

\section{Leishmanicidal and trypanocidal screening}

Trypanocidal and leishmanicidal assays of compounds 1, 2, 3, and 4 were performed using the same methodology to assay phenolic derivatives previously isolated from $C$. uniflora. ${ }^{7}$ Human monocyte cells lines THP-1 (ATCC TIB-202) were grown in RPMI-1640 medium (phenol red-free) (Sigma-Aldrich, CO. St. Louis, MO, USA) supplemented with $10 \%$ fetal bovine serum (FBS) (Life Technologies, USA), 12.5 mM HEPES (4-(2-hydroxyethyl)-1piperazineethanesulfonic acid), $100 \mathrm{U} \mathrm{mL}^{-1}$ penicillin, $100 \mu \mathrm{g} \mathrm{mL} \mathrm{s}^{-1}$ streptomycin, and $2 \mathrm{mM}$ Glutamax. Cell culture was maintained at $37{ }^{\circ} \mathrm{C}$ and $5 \% \mathrm{CO}_{2}$ incubator. L. amazonensis $\mathrm{MHOM} / \mathrm{BR} / 77 /$ LTB0016 promastigotes, expressing $\beta$-galactosidase, were maintained in Schneider's insect medium (Sigma Chemical Co., St. Louis, MO, USA) supplemented with 5\% heat inactivated FBS and 2\% human urine at $26^{\circ} \mathrm{C}$.

For the leishmanicidal screening against L. amazonensis intracellular amastigotes, THP- 1 cells $\left(3.0 \times 10^{4}\right.$ per well $)$ were cultivated in 96 well plates containing RPMI-1640 medium supplemented as described above and treated with $100 \mathrm{ng} \mathrm{mL}^{-1}$ of phorbol 12-myristate 13-acetate (PMA) for $72 \mathrm{~h}$ at $37^{\circ} \mathrm{C}$ and $5 \% \mathrm{CO}_{2}$, to allow THP-1 cells differentiation into non-dividing macrophages. ${ }^{18}$

Promastigotes $\left(4.0 \times 10^{6}\right.$ parasites per $\left.\mathrm{mL}\right)$ at 4 days of culture were washed with phosphate buffered saline (PBS), $\mathrm{pH} 7.4$, and incubated in RPMI-1640 medium supplemented with $10 \%$ human $\mathrm{AB}^{+}$serum heat-inactivated at $34^{\circ} \mathrm{C}$ for $1 \mathrm{~h}$ to parasite opsonization. After, THP-1 cells were incubated with a parasite/cell ratio of 10:1 at $34{ }^{\circ} \mathrm{C}$ for $3 \mathrm{~h}$ and $5 \% \mathrm{CO}_{2}$. After this period, infected cultures were washed with PBS to remove free parasites and nonadherent cells. Then, infected cells were incubated with complete supplemented RPMI-1640 medium $(180 \mu \mathrm{L})$ for another $24 \mathrm{~h}$ to permit the transformation of promastigotes into intracellular amastigotes.

Tulahuen strain $T$. cruzi expressing $\beta$-galactosidase ${ }^{19}$ was provided by Laboratório de Parasitologia Molecular e Celular, Centro de Pesquisas René Rachou, FIOCRUZ, Belo Horizonte, Brazil. Culturederived trypomastigotes raised from infected L929 cell line were used to infect differentiated THP-1 (4.0 x $10^{4}$ cells per well) in 96-well microplates in a parasite/cell ratio of 3:1 and incubated overnight at $37^{\circ} \mathrm{C}$ and $5 \% \mathrm{CO}_{2}$. The medium containing non-internalized parasites was removed and replaced by $180 \mu \mathrm{L}$ fresh medium.

Compounds 1-4 were dissolved in $1 \%$ dimethyl sulfoxide (DMSO) and diluted from $50 \mu \mathrm{mol} \mathrm{L}^{-1}$ to $1.56 \mu \mathrm{mol} \mathrm{L}^{-1}$. Infected cells layer was treated by addition of $20 \mu \mathrm{L}$ of each compound followed by incubation at $34{ }^{\circ} \mathrm{C}$ and $5 \% \mathrm{CO}_{2}$ for $48 \mathrm{~h}$. After treatment, cells were carefully washed with PBS and incubated for $16 \mathrm{~h}$ at $37{ }^{\circ} \mathrm{C}$ with $250 \mu \mathrm{L}$ Chlorophenolred-ß-D-galactopyranoside $100 \mu \mathrm{mol} \mathrm{L}^{-1}$ (Sigma-Aldrich Co., St. Louis, MO, USA) (CPRG) and 0,1\% Nonidet P-40 (Amresco Inc, Solon, Ohio, USA). All assays were performed in triplicate. Optical density was read at $570 / 630 \mathrm{~nm}$ in an Infinite M200 TECAN, Austria. Results were expressed as percentage (\%) growth inhibition of L. amazonensis and T. cruzi amastigotes forms. Amphotericin B $2 \mu \mathrm{mol} \mathrm{L}^{-1}$ (Bristol-Myers, Squibb) and Benznidazole $20 \mu \mathrm{mol} \mathrm{L}^{-1}$ (Sigma) were used as positive control for leishmanicidal and trypanocidal activities, respectively. As negative control group was utilized $1 \%$ DMSO.

\section{RESULTS AND DISCUSSION}

Phytochemical investigation of the dichloromethane fraction from $C$. uniflora leaves revealed the presence of four sesquiterpene 
lactones with germacranolide skeleton: $2 \alpha$-hydroxy- $8 \beta-2^{\prime}, 3^{\prime}, 5^{\prime}-$ trihydroxy-angeloyloxycostunolide (1), desacetyleupaserrin (2), $2 \alpha$-hydroxy-8 $\beta$-3'-hydroxy-2',5'-epoxyangeloyloxycostunolide (3) and ovatifolin (4). Sesquiterpene lactones were characterized using analysis of their physical (m.p.) and spectral data (1D and 2D NMR, and HRESIMS), as well as comparison with published data.

For compounds $\mathbf{1}$ and $\mathbf{3},{ }^{1} \mathrm{H}$ and ${ }^{13} \mathrm{C}$ NMR spectral data were early described by Pearce et al. ${ }^{20}$ on different solvents: DMSO- $d_{6}, \mathrm{C}_{5} \mathrm{D}_{5} \mathrm{~N}$ and $\mathrm{CDCl}_{3}-\mathrm{MeOD}(3: 1)$. In this work, NMR data of these compounds are reported for the first time in acetone- $d_{6}$, and chemical structures of compounds $\mathbf{2}$ and $\mathbf{4}$ were established by comparison of their spectral data with those previously described..$^{21,22}$

Compound 1, named $2 \alpha$-hydroxy- $8 \beta-2$ ', 3',5'-trihydroxyangeloyloxycostunolide, was obtained as an orange oil. ${ }^{1} \mathrm{H}$ NMR spectrum of this compound presented characteristic signals of an $\alpha, \beta$-unsaturated sesquiterpene lactone with an $\alpha$-methylene- $\gamma$-lactone moiety: two doublets at $\delta 6.18(1 \mathrm{H}, \mathrm{d}, J=3.6 \mathrm{~Hz}, \mathrm{H}-13 \mathrm{a})$ and $5.70(1 \mathrm{H}$, $\mathrm{d}, J=3.2 \mathrm{~Hz}, \mathrm{H}-13 \mathrm{~b}$ ) coupled with a hydrogen resonating at $\delta 3.29$ (1H, dddd, $J=8.4,3.6,3.2,1.0, \mathrm{H}-7$ ), ascribed to H-7. Hydrogen H-7 was also coupled to a hydrogen at $\delta 5.26(1 \mathrm{H}, \mathrm{dd}, J=9.9,8.4 \mathrm{~Hz})$ assigned to H-6 and to another hydrogen at $\delta 6.01(1 \mathrm{H}$, ddd, $J=4.2$, $2.8,1.0 \mathrm{~Hz}$ ) corresponding to $\mathrm{H}-8$. Two doublets signals resonating at $\delta 1.80(3 \mathrm{H}, \mathrm{d}, J=1.5 \mathrm{~Hz}, \mathrm{H}-15)$ and $1.61(3 \mathrm{H}, \mathrm{d}, J=1.2 \mathrm{~Hz}, \mathrm{H}-14)$ inferred the existence of methyl hydrogens, presenting characteristic long range allylic coupling and chemical shifts of methyl groups attached to a double bond. Ester side-chain presented four signals: at $\delta 4.35$ (d, $\left.J=11.2, \mathrm{H}-5 \mathrm{a}^{\prime}\right)$ and 4.20 (d, $J=11.2, \mathrm{H}-5 \mathrm{~b}$ '), typical of geminal methylene hydrogen close to oxygen, and $\delta 4.51(1 \mathrm{H}$, q, $J=6.6, \mathrm{H}-3$ ') coupled with a doublet at $\delta 1.50(3 \mathrm{H}, \mathrm{d}, J=6.6)$ corresponding to $\mathrm{H}-4$ ', indicating a vicinal coupling.

Carbon chemical shift values were obtained by HSQC and HMBC correlation maps. 2D NMR spectra showed the presence of 20 carbon signals that after analysis were established as three methyl, four methylene (including one methylene $s p^{2}$ at $\delta 121.7$ and other oxygenated at $\delta 67.3$ ), seven methine (of which four were oxygenated and two were alkene carbons), and six quaternary carbons (including one $s p^{3}$ oxygenated carbon, three alkene carbons, one ester carbonyl, and one lactone carbonyl). These data are consistent with a germacranolide skeleton.

Compound 3 was obtained as a white solid and showed ${ }^{1} \mathrm{H}$ NMR signals remarkably similar to compound $\mathbf{1}$, exhibiting significant differences only in chemical shift values of some signals of the side-chain. In 1, hydrogen signals $\mathrm{H}-5 \mathrm{a}$ ' and $\mathrm{H}-5 \mathrm{~b}$ ' appeared as two doublets at $\delta 4.35\left(1 \mathrm{H}, \mathrm{d}, J=11.2, \mathrm{H}-5 \mathrm{a}^{\prime}\right)$ and $4.20(1 \mathrm{H}, \mathrm{d}$, $J=11.2$, H-5b'), whereas in compound 3 these signals are more shielding, resonating at $\delta 3.83\left(1 \mathrm{H}, \mathrm{d}, J=11.0, \mathrm{H}-5 \mathrm{a}^{\prime}\right)$ and 3.67 $(1 \mathrm{H}, \mathrm{d}, J=11.0, \mathrm{H}-5 \mathrm{~b}$ '). These results suggest that the vicinal diol present in compound $\mathbf{1}$ was replaced by an epoxide ring in $\mathbf{3}$ (Figure 1). Further, molecular formula of $\mathbf{3}$ was established by HRESIMS in positive mode. HRESIMS spectrum exhibited the formation of a high-abundance sodium adduct ion peak $[\mathrm{M}+\mathrm{Na}]^{+}$

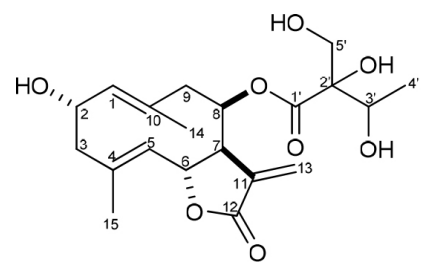

2- $\alpha$-hydroxy-8- $\beta-2$ ', 3', 5'-trihydroxyangeloyloxycostunolide (1)<smiles>C=C1C[C@H](/C=C(\C)C[C@H](O)/C=C(\C)C[C@H](OC(=O)C2(C(C)O)CO2)[C@@H]2CO2)OC1=O</smiles>

2- $\alpha$-hydroxy-8- $\beta-2$ ', 5'-epoxyangeloyloxycostunolide (3)<smiles>C=C1C[C@@H](/C=C(/C)C[C@@H](O)/C=C(\C)C[C@H](OC(=O)/C(=C\C)CO)[C@@H]2C(=C)C(=O)O[C@@H]2C)OC1=O</smiles>

Desacetyleupaserrin (2)<smiles>C=C1C(=O)O[C@@H](/C=C(\C)CC/C=C/COC(C)=O)[C@@H]1[C@@H](O)COC</smiles>

Figure 1. Sesquiterpene lactones isolated from C. uniflora leaves

at $m / z 401.1582$ (calc. for $\mathrm{C}_{20} \mathrm{H}_{26} \mathrm{NaO}_{7}, 401.1571$ ), compatible with a sesquiterpene lactone of molecular formula $\mathrm{C}_{20} \mathrm{H}_{26} \mathrm{O}_{7}$. From this deduction, chemical structure of $\mathbf{3}$ was determined as $2 \alpha$-hydroxy- $8 \beta$-3'-hydroxy-2',5'-epoxyangeloyloxycostunolide.

Compounds 1, 2, 3, and 4 are here described for the first time for $C$. uniflora species and Calea genus, but they have been identified in other plants of Asteraceae family. Desacetyleupaserrin (2) was previously reported in Helianthus pumilus, ${ }^{23}$ Eupatorium mikanioides $^{24}$ and E. glehni, ${ }^{25} 2 \alpha$-hydroxy- $8 \beta-2$ ', 3',5'-trihydroxyangeloyloxycostunolide (1) and $2 \alpha$-hydroxy- $8 \beta$-3' 'hydroxy-2', '5'epoxyangeloyloxycostunolide (3) in Helianthus resinosus, ${ }^{20}$ and ovatifolin (4) in Podanthus ovatifolius, P. mitiqui ${ }^{22,26,27}$ and Blainvillea latifolia species. $^{28}$

Results of the trypanocidal and leishmanicidal assays were expressed as percentage of growth inhibition from $T$. cruzi and $L$. amazonensis amastigotes and are summarized in Table 1. Ability of compounds to inhibit the parasites growth was evaluated at concentration of $50 \mu \mathrm{mol} \mathrm{L} \mathrm{L}^{-1}$. DMSO was used as negative control at a maximum concentration of $1 \%$ and did not interfere on parasites growth in any of bioassays. Amphotericin B at a concentration of $2.0 \mu \mathrm{mol} \mathrm{L}{ }^{-1}$ was used as positive control against $L$. amazonensis, producing $82.4 \%$ growth inhibition. Benznidazole $20 \mu \mathrm{mol} \mathrm{L}^{-1}$, the drug of choice to treat Chagas' disease, was used as positive control against $T$. cruzi, causing an $82.7 \%$ inhibitory effect on parasitic growth.

Considering the leishmanicidal activity, compound $\mathbf{4}$ exhibited higher activity, with a growth inhibition of $59.9 \%$ on L. amazonensis amastigotes, followed by $\mathbf{2}$ (19.4\%), $\mathbf{1}$ (14.4\%), and $\mathbf{3}(13.4 \%)$. Regarding the trypanocidal activity, compound $\mathbf{3}$ exhibited moderate inhibitory effect on growth of T. cruzi amastigotes (36.8\%), and compounds $\mathbf{1}$ and $\mathbf{2}$ did not showed trypanocidal activity. Although several natural sesquiterpene lactones present notable antiprotozoal

Table 1. Leishmanicidal and trypanocidal activities of isolated compounds from C. uniflora against L. amazonensis and T. cruzi

\begin{tabular}{|c|c|c|}
\hline $\begin{array}{c}\text { Tested compounds } \\
\text { Concentration }\left(50 \mu \mathrm{mol} \mathrm{L}{ }^{-1}\right)\end{array}$ & $\begin{array}{l}\text { \% Growth inhibition } \pm \mathrm{SD} \\
\text { L. amazonensis amastigotes }\end{array}$ & $\begin{array}{c}\text { \% Growth inhibition } \pm \mathrm{SD} \\
\text { T. cruzi amastigotes }\end{array}$ \\
\hline 1 & $14.4( \pm 1.5)$ & No activity \\
\hline 2 & $19.4( \pm 2.5)$ & No activity \\
\hline 3 & $13.4( \pm 2.0)$ & $36.8( \pm 1.8)$ \\
\hline 4 & $59.9( \pm 1.8)$ & $5.0( \pm 1.1)$ \\
\hline DMSO $1 \%$ & 0 & 0 \\
\hline Benznidazole $20 \mu \mathrm{mol} \mathrm{L}-1$ & - & $82.7( \pm 0.9)$ \\
\hline Amphotericin B $2 \mu \mathrm{mol} \mathrm{L}-1$ & $82.4( \pm 1.9)$ & - \\
\hline
\end{tabular}


activity, compounds isolated herein did not show promising effect against the morphological stages of L. amazonensis and T. cruzi tested strains.

\section{CONCLUSIONS}

Phytochemical analyses of C. uniflora leaves led to the isolation and structural determination of four germacranolide-type sesquiterpene lactones, all isolated for the first time for the $C$. uniflora species and Calea genus. These results are in agreement with previous chemical studies, which have confirmed that Calea species are rich in sesquiterpene lactones. It is important to point out that the identification of chemical constituents is truly relevant for ensuring the safety and efectiveness of popular medicine. Regarding the antiprotozoal activity, the assays revealed that ovatifolin (4) was the most bioactive compound against $L$. amazonensis intracellular amastigotes and none of isolated sesquiterpene lactones showed promising trypanocidal activity.

\section{SUPPLEMENTARY MATERIAL}

1D and 2D-NMR, and HRESIMS data of compounds $\mathbf{1}$ and $\mathbf{3}$ (Figures 1S-9S) are available free of charge in the supplementary material at http://quimicanova.sbq.org.br/ as PDF.

\section{ACKNOWLEDGMENTS}

This research was supported by Conselho Nacional de Desenvolvimento Científico e Tecnológico (CNPq), Coordenação de Aperfeiçoamento de Pessoal de Nível Superior (CAPES) and Universidade Federal de Santa Catarina (UFSC).

\section{REFERENCES}

1. Ferraz, A. B. F.; Silvia, S. P.; De Oliveira, P. A.; Lino, F. L.; Picada, J. N.; Pereira, P.; Lat. Am. J. Pharm. 2009, $28,858$.

2. Pio Corrêa, M.; Dicionário das plantas úteis do Brasil e das exóticas cultivadas, Imprensa Nacional: Rio de Janeiro, 1984, p. 123.

3. Zank, S.; Dissertação de Mestrado, Universidade Federal de Santa Catarina, Brasil, 2011.

4. Ramos, L. S.; Cardoso, P. S.; Freitas, M. D.; Panhan, R.; Borges, M. S.; Citadini-Zanette, V.; Barlow, J. W.; Amaral, P. A.; Dalbó, S.; An. Acad. Bras. Cienc. 2016, 88, 2319.

5. Do Nascimento, A. M.; Salvador, M. J.; Candido, R. C.; de Albuquerque, S.; Oliveira, D. C. R. J.; J. Pharm. Pharmacol. 2004, 56, 663.
6. Do Nascimento, A. M.; Costa, F. C.; Thiemann, O. H.; Oliveira, D. C. R.; Z. Naturforsch C. J. Biosci. 2007, 62, 353.

7. Lima, T. C.; Souza, R. J.; Santos, A. D. C.; Moraes, M. H.; Biondo, N. E.; Barison, A.; Steindel, M.; Biavatti, M. W.; Nat. Prod. Res. 2016, 30, 551.

8. Rodrigues-Torres, V. N.; Machado, J. D.; Ramos, L. S.; Paghan, R.; Kautz, J.; Rouaud, I.; Sauvager, A.; Tomasi, S.; Dévéhat, S. L.; Dalbó, S.; Amaral, P. A.; J. Med. Plants Res. 2016, 10, 695.

9. Rosa, J. S.; de Mello, S. V. G. V.; Vicente, G.; Moon, Y. J. K.; Daltoe, F. P.; Lima, T. C.; Frode, T.; Int. Immunopharmacol. 2017, 42, 139.

10. Babaei, G.; Aliarab, A.; Abroon, S.; Rasmi, Y.; Aziz, S. G.; Biomed. Pharmacother. 2018, 106, 239.

11. Butturini, E.; Di Paola, R.; Suzuki, H.; Paterniti, I.; Ahmad, A.; Mariotto, S.; Cruzzocrea, S.; Eur. J. Pharmacol. 2014, 730, 107.

12. Gutiérrez, R. M. P.; Ramirez, A. M.; Food Sci. Biotechnol. 2016, 25 , 1135 .

13. Mofidi, T. S.; Nejad, E. S.; Salehi, P.; Sonboli, A.; Marzieh, T.; Kaiser, M.; Hamburger, M.; Farimani, M. M.; Planta Med. 2019, 85, 424.

14. Karioti, A.; Skaltsa, H.; Zhang, X.; Tonge, P. J.; Perozzo, R.; Kaiser, M.; Franblau, S. G.; Tsdemir, D.; Phytomedicine 2008, 15, 1125.

15. Amorim, M. H.; Gil da Costa, R. M.; Lopes, C.; Bastos, M. M.; Crit. Rev. Toxicol. 2013, 43, 559.

16. Caldas, L. A.; Yoshinaga, M. L.; Ferreira, M. J. P.; Lago, J. H. G.; de Souza, A.B.; Laurenti, M. D.; Passero, L. F. D.; Sartorelli, P.; Bioorg. Chem. 2019, 83, 348.

17. Wu, H.; Fronczek, F. R.; Burandt, C. L. Jr.; Zjawiony. J. K.; Planta Med. 2011, 77, 749 .

18. Schwende, H.; Fitzke, E.; Ambs, P.; Dieter, P.; J. Leukoc. Biol. 1996, 59, 555.

19. Buckner, F.; Verlinde, C. L. M. J.; la Flamme, A. C.; van Voorhis, W. C.; Antimicrob. Agents Chemother. 1996, 40, 2592.

20. Pearce, J.; Gershenzon, J.; Mabry, T. J.; Phytochemistry 1985, 25, 159.

21. Ohno, N.; Mabry, T. J.; Phytochemistry 1979, 16, 1003.

22. Cespedes, C. L.; Ramirez-Apan, T.; Uchida, A.; Calderon, J. S.; Hoenenisen, M.; Silva, M.; Rev. Latinoam. Quim. 2000, 28, 125.

23. Herz, W.; De Groote, R.; Phytochemistry 1977, 16, 1307.

24. Herz, W.; Kumar, N.; Blount, J. F. A.; J. Org. Chem. 1980, 45, 489.

25. Tori, M.; Morishita, N.; Hirota, N.; Saito, Y.; Nakashima, K.; Sono, M.; Tnaka, M.; Utagawa, A.; Hirpta, H.; Chem. Pharm. Bull. (Tokyo) 2008, 56,677 .

26. Hoeneisen, M.; Kodama, M.; Ito, S.; Phytochemistry 1981, 20, 1743.

27. Hoeneisen, M.; Sicva, M.; Bohlmann, F.; Phytochemistry 1980, 19, 2765.

28. Sawaikar, D. D.; Rojatkar, S. R.; Nagasampagi, B. A.; Phytochemistry 1997, 46, 375 